\title{
100
}

Rupantaran : A Multidisciplinary Journal

Vol. IV : pp 100-111, October, 2020

ISSN : 2091-0061

https://doi.org/10.3126/rupantaran.v4i1.34195

Research Management Cell (RMC)

Dhankuta Multiple Campus, Dhankuta

Tribhuvan University, Nepal

\section{Balancing Professional Life and Motherhood: Lived Experiences of Female English Language Teachers in Nepal}

\author{
Krishna Kumari Khadka ${ }^{1}$ \\ Email: krishnakumari.khadka@gmail.com
}

\section{Abstract}

Professional mothers' responsibility regarding motherhood and a professional life management is highly confronted with gender roles whether to quit or continue the job. Understanding about the intersection between motherhood and professional life helps to navigate and negotiate the dual roles. This phenomenological study is based on qualitative method, which explores how female English language teachers are able to maintain their social and professional identity in Nepal. In this research I analyze the experiences of three secondary level female English language teachers with a focus on dual roles, multiple coping strategies and gender issues on its center. The study reveals that, balancing motherhood and professionalism as female teachers have a lot of challenges which results the incompatibility on both roles. The sensitive nature of job and inflexible and monotonous duties at home made female teachers impossible to undertake their duties perfectly at schools and at home vice-versa. Such role becomes tougher to them due to multilingual environment in the classrooms. This study can be the trajectory bridge to the professional women to get some ideas to balance motherhood and their professional lives.

Key Words: imbalances, motherhood, professionalism, responsibility, transmission

\section{Introduction}

Balancing the responsibility of motherhood and climbing the successful career development stairs is not an easy task for professional women in Nepal. It requires a lot of struggle, motivation, devotion, enthusiasm, passion, contribution, sacrifice and sincerity. Female English language teachers face multitude of challenges

1. Ms. Khadka is a visiting faculty at Nepal Open University, Nepal. 
which are related to high -quality standardization in professionalism and personal responsibilities at home. Carrying a single bag of dream and branching the duties in multiple sectors is very hard for me as I experienced as a professional and a mother. So, being a professional and fulfilling the duties of a mother requires significant time contributions (Harrision, 2008) the ability to manage several tasks (Wolf-Wendle $\&$ Ward, 2006), significant emotional investment, and a high amount of motivation.

Professional women are caught between a wide range of duties and responsibilities such as caring for their children, engaging in household chores and fulfilling professional obligations in formal and informal settings. Mothers as English language teachers have the duties like attending classes regularly, supervising students' assignment, making the portfolio of the students, counseling the children, dealing with parents and administration, organizing and attending the meetings, attending the training, updating self on the profession related issues and so on. On the other hand, English teachers as mothers have the duties like feeding the children and making them sleep on time, changing diapers, cooking for them, cleaning for them, spending several nights awake for them, supervising for their home assignment, dropping them and picking them back from schools, taking them to hospitals during sickness. (Sarpong, 2017) maintaining the better relationship with friends, families and the people of the societies, taking care of the old age people at home and many more. The dual role at once is major interruption to get and handle extra opportunities. Mothers inductively advocate that, they neither became the perfect mother nor the perfect worker. A pile of their everyday work limits their time to think critically, kills their creativity and makes them busy on unproductive works.

Female English language teachers' career building plays vital role in teacher professional development. For the well planned teachers' professional development it is necessary to understand how teachers' 'live', 'feel' and 'handle the situations' in their professional transformation to develop adequate support to manage multiple responsibilities at once like handling the profession and the duties of motherhood. Those understandings require involving teachers in telling, evaluating, connecting and critically reflecting themselves on their own hidden stories of pain and pleasure which are related to the professional progress, social identity and all round well being of them in formal and informal settings. This study is significant as it explores the struggles, emotions and professional transmission of motherhood to professionalism and professionalism to motherhood which is expected to provide critical insights into what legal, family and social support female English language teachers need for their professional development.

There are efforts made to promote girl's education enrollment in school which is expected to increase the number of female workers in offices with well paid jobs. 
The increased access of girls to education helps them in many ways such as decision making, and economic independence. But on the other hand, it has been creating so many seen and unseen problems in females' lifestyle. Mothers who are professionals have to play multiple roles at once due to which problems regarding professionalism and motherhood are increasing day to day. However, the reputed organizations working for the wellbeing of English Language teachers also do not have official figure about the number of female English teachers working at the school and the university level. In addition, research evidence is scare regarding how female teachers of English are balancing their motherhood and professionalism in Nepal. Therefore, I am interested to explore the existing reality in this field as I am also facing the challenges playing the dual roles as a mother and a professional at once.

The main objective of this qualitative phenomenological study is to explore how Nepalese female teachers of English Language balance their professionalism and motherhood. To obtain the information, research questions like, how challenging is the time for a woman while playing a dual role at once as a mother and a professional? What can be the role of gender and can be the best coping up strategies were asked in formal and informal settings. It mainly focuses on the opportunities and challenges, multiple coping up strategies and the particular responsibilities determined due to gender on formal and informal sectors of their work. Likewise, this research is centered on Nepalese female teachers of English at secondary level teaching in both private and public schools varying from far east to far west. By nature phenomenological study, like this article, includes a small number of respondents. The findings of this research may or may not be equally applicable to all, but it can be the milestone to understand the challenges faced by female English language teachers.

\section{Methods and Materials}

This qualitative research is based on interepreativism which adopts phenomenological research design to collect and analyze data. As a qualitative method, phenomenological study focuses on the in- depth interview and analysis of female English language teachers who are navigating dual roles as a professional and a mother in private and public schools of Nepal. The participants of my research are from Far East to far west including Kathmandu valley. This phenomenological study pays attention to the lived experiences of participants and draws the common themes from the analysis of their experiences. As the demand of this research, I purposefully selected three female English teachers who are mother and living or not living with husband but must be living with their children, among these three one is from Far East who belongs to public school and is in the permanent category. Likewise, the next participant is from Far West and teaches in public school as a permanent teacher. But 
another participant is from private school and she is the English teacher and the vice principal from Kathmandu valley. The experiences of these teachers were collected through a series of in-depth interview in three different phases. The first phase was rapport building, second was the in-depth interview and the third phase was the follow up phase respectively. Due to COVID -19 pandemic I was unable to meet the participant in face to face mode so I used ZOOM app for formal and informal interactions. At first, asking and taking their phone numbers from the education office of village rural municipality of the participants of their respective district, I made a phone call and explained them in detail about the purpose of my research and asked for the permission. When I was granted permission; I asked them for their appropriate time. Secondly, I created my personal ZOOM ID and provided them the link. When we started to talk in an informal way, I started recording as I was granted the permission earlier. I noticed and wrote some information regarding their facial expression, gestures, sitting styles and so on during the interview as field notes. The interviews and field notes were transcribed and the transcription was coded by using theametic network analysis technique .According to Brown and Clerk, in thematic network analysis, I generated basic themes, organizing themes and global themes respectively. From each narrative under global themes related to balancing motherhood and professionalism and interpreted those global themes using thematic network analysis technique. This approach helped me to understand how each female English teacher's experiences are unique, critical and meaningful to draw the exact status of female teachers and some policy related situations for further recommendations. Female English Language teachers' experiences on professionalism and motherhood, voices, realities, identities, challenges, opportunities, coping up strategies, and gender issues were kept at the center of the data analysis and interpretation process.

As a researcher, to maintain the ethical consent, I also made them assure that the information provided by them to me never be misused for any other purpose than this study. It means that, in phenomenological study, ethical issues particularly very true information and their safety is important. Realizing this issue, I protected the respondents' right to anonymity by using their pseudonyms throughout my study. In this study, I collected detail narratives of three teachers of public and private schools. The limitation of this study was that I could not include the teachers of all categories like temporary, contract, Rahat, PCF and so on.

\section{Results and Discussions}

\section{Balance Between Profession and Motherhood}

Balancing the responsibilities of motherhood and climbing the career to professionalism may be daunting to female English language teachers because of 
the fluctuations occurred at the time of work at home and in schools. They were caught between the demands of caring their children, engaging in household chores and fulfilling professional obligations in their workplace. Sabina (pseudonym) the participant of my research and a professional mother said: "Hum...professional mothers' multiple roles exhaust their supply of time and energy to their babies is always less than they expected." The desired out-comes of the children is only possible when parents prioritized their intimacy as potential initiatives to transform them from innocent to matured being. The gender equality culture and adequate support from the family help to juggle professionalism and motherhood to the professional mother. Multiple roles at once make mothers' duty inflexible, dependable, less productive, and underperformed. Their effort to balance both roles simultaneously puts them under tremendous pressure. Sarpong (2017), states handling dual roles require significant time and energy commitments to a mother (Harrison, 2008), the ability to manage multiple tasks (Wolf- Wendel \&Ward, 2006) significant emotional investment, and high amount of energy and stamina is needed. As a professional mother I also caught between the wide range of responsibilities at home and in school. The unexpected challenges result undesired outcomes both at home and in school ranging from children's behavior to students' behavior. Therefore, mother as a teacher is the trajectory figure to advocate both roles with potential energy, time investment and self motivation. "Smooth on -going of dual roles and embracing multiple challenges in a meaningful way is not an easy path to walk on" stated Radhka (pseudonym). So, both roles require sufficient seriousness and time contribution for the integration of identity and solidarity to a professional mother. Power of transforming obstacles into opportunities and shaping the professional position is critical which require extra effort.

Professional responsibilities of a secondary female English teacher are highly sensible which are totally associated to shape the future occurring of the students. Managing diversity and creating appropriate pedagogical environment in multilingual classrooms require great effort, passion, devotion and dedication from the facilitators. In Nepal, learners have high expectation regarding English. It is taken as the language of power, prestige and globalization where English teachers' role is significant to bring such expectation into reality. Although parents have such expectation, the learning achievement of the learners and parents expectations are mis-matched due to various reasons. "In the context of the students of public schools in Nepal, they have to work from morning to evening in order to satisfy their hunger" stated Sabina, "Most of them are domestic workers" said Sita. In such scenario, mothers as professional have to work extra hours to build their learning foundation and uplift their learning outcomes in an optimistic way. Professional mothers know that their role is crucial for their baby's all round development and wellbeing but their compulsion is to leave the children either at home or in childcare centers from early morning to late evening to 
contribute for their work. "Economic advancement and maintaining social prestige is another factor which keeps female in work pressure", stated Radhika. So, the limitless unseen responsibilities neither realized by family members nor the co-workers at offices make professional mothers feel guilty about their inability to complete task on time. As English is highly taught and learnt foreign language, teachers of English need to think, re-think, study, re-study, plan, re-plan search, re-search, evaluate, re-evaluate to know the ground level of the learners and provide them feedback. The demand of English is high so does the expectation of parents all around the globe. Parents send their children to English medium schools for mainly three reasons as English is taken as the matter of prestige in the society, it is the key to open the door of success as the wide range of job opportunities will be easier to get and handle in the future of their children and it opens the door to abroad studies. The diversified classrooms regarding the level of the learners, linguistic background, socio-cultural status, economic status of the learner, and students' geographical location are the few obstacles which cerate number of hazards for the productive and high quality performance of the female English teachers.

The provision of inadequate maternity leave granted by the government for the female teachers is unsupportive factor to enhance their professionalism. Recovery of women from childbirth stress and their resumption of work and motherhood responsibilities are mainly influenced by factors like pre-existing health status, parity, breastfeeding, the accessibility of social help from family and companions and work related issues e.g. timing of return to work, work pressure, and working environment. Sabina (pseudonym) one of the participants said: "Professional mothers either have to cease the job or conceal the breastfeeding". The time to those mothers after giving birth to their baby to till six months is really critical and challenging that "There are no such words in dictionary to describe such situation" said Sita. According to the constitution of Nepal, it is the fundamental right of all mothers to get maternity leave for 60 days in the past and 98 days at present those who are involved in the government services. However, the certain allocated time for leave is not sufficient for mothers as well as the babies. The constitution has granted the right to the child to get breastfed for at least six months of their early life. But that is almost impossible in case of professional women. In case of private organizations, females either have to take nonpaying leave or they have to quiet the job just because of being mother. Oshagbemi, T. (1997), stated that, regardless of the decision women made about taking a maternity leave or not, they were met with negative attitudes from others. When mothers take maternity leave, they are seen as less committed to their jobs and when they do not take leave, they are viewed as bad mothers. So, this double role makes everything very much challenging for those women to be successful in their career. 
The linguistic development of the English teachers' children is zeo-paradised. Mothers of English most frequently use English language to handle multilingual class. So their language is not fixed like other subject teachers'. Mothers speak dual language at once with their children at home. So the toddlers at home are confused with their mother's language. Its negative impact is with their children not only that much "The power of English is killing the linguistic development of English teachers' children as well" stated Radhika (pseudonym). The most important stage of brain development is the beginning of life, starting in the womb and then the first year of life. By the age of three, a child's brain has reached almost $90 \%$ of its adult size Oshagbemi, (1997). "The children who are growing up with high amount of linguistic exposure being with their mother in the single language is learnt language faster and clearer." Radhika (pseudonym). So the environment and level of exposure that we provide to the babies during their early stages of their life determine their linguistic competencies. So this phenomenon should be taken seriously on time and should not penalize our kids due to language. "It is highly recommended to focus on only one language to the children in their initial stages of learning" Sita (pseudonyms) said. Parents' language should not work as penalty to their children whether they are teachers of English or any other subjects. As I also experienced, the issue seems very normal and unnoticed but it brings irreparable loss on the linguistic development of the children.

The brain development and neuron pruning is the result of mothers' attachment with their children. It is seen that, children with a lot of emotional support at home are more confident, supportive and their academic performance is also better. There is increasing evidence that the mothers' lack of love and care during their infancy can lead to long-term mental health problems and reduced overall potential and happiness of the babies. Children who got caring support of their parents are much more responsible than the others. On the other hand students with high exposure on language learning from their mothers have higher excellence in their academic performance. The artificial sentiment and sympathy to the babies and the students work as an intoxicant which brings complications and contradictions on their lives. Therefore, professional mothers should have that unique management skill which balances their professionalism and motherhood keeping behind all those hazards.

\section{Coping with Multiple Challenge}

The reconciliation coping strategies are mandatory to reduce negative impacts of work stress to the professional mother at home and in school. Time changes, the circumstances change, life does not run as smoothly as we think. "Nothing runs as we plan" stated Sabina (pseudonym). Sometimes situations become worse at home and in school, either due to overdue work or any other work related pressures. In such scenario, female English teachers use different coping up techniques like self 
motivation, spending quality time with family and friends, taking the support of technological devices to reduce work load, making proper routine and following them strictly in order to energize themselves. As Radhika (pseudonym) stated:

Regular exercises and meditation in the morning and in the evening also support to reduce the work stress and keep people cool. If mothers can create supportive family environment in the family it would be easier to maintain everything.

The fluctuations occur in different time interval. Mothers plan one thing but happen to be another. However, the evidences show that women who make choices for balancing motherhood and profession are seen happier and more committed to their work. As Sabina stated "Mothers always look happy and caring as professionals although they encounter lots of hazards and hurdles." A perfect balance between profession and motherhood benefits as it is directly linked to better life satisfaction and subsequently to workers being more productive, creative and efficient (Zelenski, Murphy, \& Jenkins, 2008). Female teachers of English cope up the situation with the proper management of time and work. Therefore, strong preferences of those coping up strategies help to motivate with positive energy which maintain a sense of balance between personal and professional responsibilities to mothers as professionals. Mothers always charge themselves as continuous effort on a particular issue gives better satisfaction though it is tough to work continuously.

Female teachers of English strengthen teamwork, sense of community, confidence and more efficient work practices to change numerous hazards as opportunities. Multiple roles at once are taken as opportunities rather than obstacles because "They are habituated to face them", Radhika stated. Those females who handle double roles are independent in economic status and other social situations, like decision making, maintaining relationships etc. Their independency makes them more confident, cooperative, creative and sincere. They learn to respect the challenging situations. Self respect is improved which energies them to explore their internal capacity in their professionalism. Siber, (1974), mentions that the dual role builds up a well rounded personality, and feelings of self-gratification among women. But the long working hours, schedule inflexibility, shift of work requirements and over time evening duties regarding household works may create over stress to the female. Being female English teachers and handling dual role is again hectic job because making students able to learn in second language requires a lot exposure, motivation and conscience from both teachers and students. The phenomena of motherhood and professionalism are both mutually exclusive and contradictory due to their uncertainties and limitless responsibilities.

The mothers' need for their children is required in every stage. Children pass through different social development stages. Those stages of developments support 
them to adjust in the society where they are being grown up. Social development is such the crucial factor which is intertwined with other areas of development such as cognitive, physical, emotional and linguistic. It also may include children's ability to get along with and respect others, such as those of a different race, ethnicity, religion, sexual orientation or economic background. Basically, social skills include a range of pro-social behaviors, such as empathy and concern for the feelings of others, cooperation, sharing and perspective taking, all of which are positively associated with children's success both in school and in non academic setting Emslie, C. and Hunt, K. (2009) So, to cope up with students and their babies at home work division among the family members is needed to practice but that is also almost not possible in the Nepalese societies. If the provisions of government are made easier to take leave for teachers it would be easier to the female teachers to handle multiple responsibilities at once during the early ages of their children.

\section{Gender Sensitivity at Home and in Offices}

Gender sensitivity and equality at home and in offices can promote healthy environment to multiply work efficiency level of professional mothers. There should not be any sorts of discrimination among the people in offices due to gender than only the target goal is easy to fulfill. The equal support from all the family members and the spousal support is most to the professional mothers. Female English language teachers have mixed experience regarding gender issues, the women who are working in literate societies are facing less challenges in comparison to those female who work in illiterate societies. As Radhika mentioned:

For female English teachers complexities are at both places i.e at homes and in offices. Most frequently the female voices are unheard and less considered. Even in schools the major and better opportunities are taken by male teachers and the minor opportunities are given to female teachers. If there is male head teacher he speaks one thing and does the other regarding the issues of female teachers and girls students.

We still have such societies which consider female as the second class citizens." Their position is determined due to giving birth to baby whether boy or girl" said Sita. There are societies and the people who give high priority to son. Females are victimized due to giving birth to a daughter, "tortures are very tough even much difficult to forget," said Sita. So, "Still women curse themselves getting birth as a female and giving birth as a daughter" said Sabina. People, especially males never understand the core feeling of the females. "If science can invent miracle, females want such miracle to be happened in near future on which male can give birth to the baby and feel the feelings of motherhood as how difficult it is" Sita (pseudo name) responded it. 
Even women within the same household can face different constraints based on their status relative to other family members. For examples, in partricheal communities a mother-in-law has more power at home than does her daughter- in-law.

Females have to sacrifice her so many wishes after their marriage. In fact, women want to work for economic self-sufficiency which is needed to liberate women from male domination, and it is achieved through "better-paying jobs" with comfortable time schedules. But comfortable and better paying jobs are very hard to get in the context of Nepal by Nepalese women.

Female English teachers have triple load than other females they have to handle the job, career, and babies at once. Although they earn themselves they do not have their right to claim their own earnings in some of the societies. Although there are policies to address this issue, there is a need of proper implementation of these policies to ensure female rights. It means, females are ready to face pain and sacrifice their lives in order to save the prestige of the family and themselves. Constraints on women's power and choices, therefore, relate not only to their individual characteristics but also to the contextual factors that mediate these, such as their legal rights, community norms or household structures. As Radhika experienced and stated:

Still the male dominant behavious and practices are not eliminated in offices and at home. Females have to leave their job due to being pregnant. They are unable to work effectively during their pregnancy due to which they get unnecessary torture from their boss or the supervisor. In fact that is the time on which they need much care, support and love from the people of their surroundings.

Such happenings are not only heart- touching they can be the milestone to change the systems as well. People who face the problem do not let the others to do the same when they are in the post. The good example is again the same respondent of my research Radhika, when she became the vice principle of her school she brought the system of granting paid leave for two months to those female who are pregnant. So the bad instruments also sometimes sound better when it is in the hand of fine artist. Gender equality, is not an easy job to bring in practices and make them practicable in every society. It neither be implemented nor get the targeted goal perfectly till the time each individual washes their deeply rooted traditional concept to see females as second class citizens either at home or in offices. Gender equality is not seen in offices and at home unless and until it is strictly practiced to enhance motherhood and professionalism. 


\section{Conclusion}

Balancing profession and motherhood carried a lot of challenges due to the difficulty in balancing household and professional roles to secondary level female English teachers in Nepal. I also agree with (Dunifon and Gill, 2013) as professional English teachers as mothers are caught between monotonous and heavy responsibilities due to the sensitive nature of the job. Moreover, female English language teachers are in high work pressures at school because of diversity in the class as multilingual classrooms. Spousal support is the most important form of support, followed by the external families which ease the work pressure of professional mothers. However, women involved in the professional jobs are getting less support from their spouse because there is less practice of work division and teamwork at home and in office in Nepal. Lack of family support and motivation it is very tough to balance profession and motherhood to female English language teachers in Nepal. The socially constructed gender role hinders their professional life much. Existing gender discrimination affects one's development ultimately influencing the social and professional identity of female English teachers

Conclusively, there is the need to emphasize and understand the sensitivity roles of mothers as professionals to provide appropriate support and encourage them to handle both roles without any hazards. In addition, policy makers should devise strategies for empowering female for bringing positive changes to the traditional perspective that motherhood and professional responsibilities cannot be handled simultaneously by single person at the same time. The structure of the schools, nature of the job and the deep rooted partericheal thought of the people should be changed more or less and be female friendly. Also, the discussion and discourse should be initiated to change traditional roles of a female as professional, as professional mothers cannot handle all the socially constructed traditional roles. The environment at home and schools should be changed and be female supportive. Finally, it is needed to realize that the positive transformation of the societies is only possible when some deeply rooted traditional thoughts are practically removed and put pressures for the effective implementation of the policies officially made for women empowerment.

\section{References}

Dunifon, R,.\& Gill, L.(2013). Maternal employment and child well-being, Comell University (Parenting in context research series). Comell University.

Emslie, C. and Hunt, K. (2009). Live to Work or Work to Live? A qualitative Study of Gender and Work- live Balance among Men and Women in Mid-Life. Gender, Work and Organization, 16(1):151-172 
Harrison, R. (2008). Evolving trends in balancing work and family for future academic physicians A: role for personal stories. Medical Teacher, 30, 316-318.

Oshagbemi, T.(1997). Job Satisfication profiles of university teachers. Journal of Mangerial Psychology, 12(1), 27-39 and Career: How can women combine? Retrived from https://bit.ly/2VVqmif

Sarpong, R.(2017). Motherhood and Career: How can women combine? Retrived from https://bit.ly/2VVqmjf

Sieber, S.(1974).Towards a theory of role accumulation. American Sociological Review, 39 (4), 11.

Wolf- Wendel, L.,\& Ward, K.(2006). Academic life and motherhood: Variations by institutional type. Higher Education,52(3),487-521.

Zelenski, John M., Steven A. Murphy, and David A. Jenkins (2008). The happyproductive worker thesis revisited. Journal of Happiness Studies (9) 521537. 